\title{
Probable medications overuse headaches: validation of a brief easy-to-use screening tool in a headache centre
}

\author{
Virginie Dousset ${ }^{1 *}$, Martial Maud ${ }^{1}$, Mélanie Legoff², Françoise Radat ${ }^{1}$, Bruno Brochet $^{1}$, Jean-François Dartigues ${ }^{2}$ \\ and Tobias Kurth ${ }^{3,4}$
}

\begin{abstract}
Background: To validate a rapid questionnaire as a screening tool, because application of the diagnostic revised criteria of the ICHD-II for medication overuse headache $(\mathrm{MOH})$ requires experience for the physician and is time-consuming.

Methods: ICHD-II criteria for probable $\mathrm{MOH}(\mathrm{pMOH})$ were transformed in questions formulated in such a way that they could be self-administered, easily understood, and quickly filled out. We compared this questionnaire to the gold standard: the diagnosis made by headache specialists, based on the the ICHD-II criteria. Patients who were consulting for $\mathrm{pMOH}$ or migraine for the first time were consecutively included. As validity indicators, we calculated sensitivity, specificity, positive and negative predictive values of the items.

Results: Seventy-nine patients were screened, 77 included, 2 female patients excluded. Forty-two patients have been considered as suffering from $\mathrm{pMOH}, 35$ patients suffered from migraine without medication overuse. The association of the question "do you take a treatment for attacks more than 10 days per month" and the question "is this intake on a regular basis?" had a sensitivity of $95.2 \%$ and a specificity of $80 \%$.

Conclusion: This screening tool can detect $\mathrm{pMOH}$ with a sensitivity that could be of interest to screen patients in clinical practice and to pre-include patients for research as epidemiological studies.
\end{abstract}

Keywords: Medications overuse headaches; Screening tool; Validation; Questionnaire; Sensitivity; Specificity

\section{Background}

The prevalence of chronic daily headaches with medication overuse is around $1.5 \%$ of the general population, with prevalence figures being very similar across different countries. They account for $10 \%$ to $78 \%$ of patients seen in headache centres [1]. Medication overuse headache $(\mathrm{MOH})$ decreases the quality of life and accounts for reduced efficiency at work. Population-based and clinical data reflects the importance of this public health problem [2].

The 2nd edition of the International classification of headache disorders (ICHD-II) defined $\mathrm{MOH}$ as a migrainetype headache: 1 present on $\geq 15$ days per month with at least 1 of the following characteristics: bilateral, pressing/

\footnotetext{
*Correspondence: virginie.dousset@chu-bordeaux.fr

${ }^{1}$ Centre Douleur Chronique, Hôpital Pellegrin, Place Amélie Raba Léon, 33 076 Bordeaux, Cedex, France

Full list of author information is available at the end of the article
}

tightening quality, mild or moderate intensity; [3] associated with use of acute treatment for headache on a regular basis for more than 3 months [1] that developed or markedly worsened during medication overuse [4] that resolved or reverted to its previous pattern within 2 months after discontinuation of the offending medication [5]. Subsequent revision proposed to eliminate the headache characteristics [3] and to delete the last criterion in order to allow the establishment of $\mathrm{MOH}$ diagnosis when the patient suffers from the disorder and not only after the medication withdrawal [4]. This change suggested by Olesen has not been officially implemented and correct formulation for $\mathrm{MOH}$ before withdrawal should be probable $\mathrm{MOH}$ (pMOH). The IHS classification is an explicit clinical criterion so that the diagnosis of $\mathrm{pMOH}$ does not require any specific examination that is needed only to exclude a symptomatic origin. Application 
of the operational diagnostic revised criteria of the ICHDII allows making the diagnosis on the basis of consumption of medication (number of days monthly) and a worsening of the headache during the time of medication intake. However, this clinical diagnosis with a face-to-face interview is the gold standard and requires clinical experience for the physician, and enough time to question patients precisely, to specify ICHD-II criteria, and to specify the diagnosis of primary headache, more frequently migraine, which has been the basis for the development of the $\mathrm{MOH}$. This is time-consuming.

In this clinical context, a less time consuming tool would be of interest. We have developed a 4 item questionnaire evaluating the frequency of headaches and the amount of medication consumption used to treat the attacks and compared sensitivity and specificity of this in migraine patients and $\mathrm{MOH}$ patients. Indeed, such a tool would be useful in clinical practice and for research, to pre-include patients for epidemiological studies.

\section{Methods}

\section{Design}

We evaluated the accuracy of the rapid evaluation of headaches and medication used to treat the attacks consumption in a sample of consecutive headache patients seen at the Bordeaux Headache Centre for their first visit. Our goal was to establish the validity of a brief screening instrument that uses among other things selfreporting of use of acute treatment for headache by the patient and has both the sensitivity and specificity that would make it useful in the outpatient headache centres, and in general practitioner practices. The validity study required the comparison of answers of medication overuse headache sufferers to the answers of migraine sufferers, with the gold standard diagnosis done by two neurologists specialised in headache. The study was conducted in France in the Bordeaux headache centre. Because the setting of intended use was at first pain or headache centres, our validation study occurred in an outpatient headache centre (a specialized headache centre of a teaching hospital).

\section{Patients}

All men and women aged 18 years or more who were visiting for migraine or probable $\mathrm{MOH}$ identified by their general practitioner were consecutively pre included. Pre inclusion required the ability to read and write French. They filled out the questionnaire in the waiting room. Then definitive inclusion was done after the diagnosis of migraine without aura or migraine with aura, or migraine without or with aura plus $\mathrm{pMOH}$ by one of the headache specialist during the face-to-face interview according to the 2004 ICHD-II [3] criteria.

Other primary headaches or secondary headaches were exclusion criteria. Patients were enrolled after providing their informed consent. We did not collect any personal information so that an ethics vote was not necessary.

\section{Questionnaire elaboration}

The criteria defined $\mathrm{pMOH}$ as (A) headache present on $\geq 15$ days per month, (B) associated with use of acute treatment for headache on a regular basis for more than 3 months ; (C) that developed or markedly worsened during medication overuse; (D) medication overuse is defined as 10 days or more of intake in triptans, ergot alkaloids, mixed analgesics or opioïds, and 15 days or more of analgesics/NSAIDs or the combined use of more than one substance. These criteria were transformed into questions by experts of $\mathrm{MOH}$. They were formulated in such a way that they could be self-administered, quickly filled out and easily understood. The questions were: 1 . Do you have headaches for more than 15 days/month? 2. Do you take treatment for attacks more than 10 days per month? 3 . Is it for more than 3 months? 4. Is drug intake regular? (Table 1). The Item $\mathrm{C}$ of ICHD-II criteria (the headache worsened with the overuse of the acute medications) has been marked out because it's a difficult question for the patients who answered about the intake of the medication to relieve the headache. In order to verify that all questions could be easily understood, we submitted the questionnaire to a sample of patients before beginning the study. Questions should have

Table 1 ICHD-II criteria for PMOH and self questionnaire

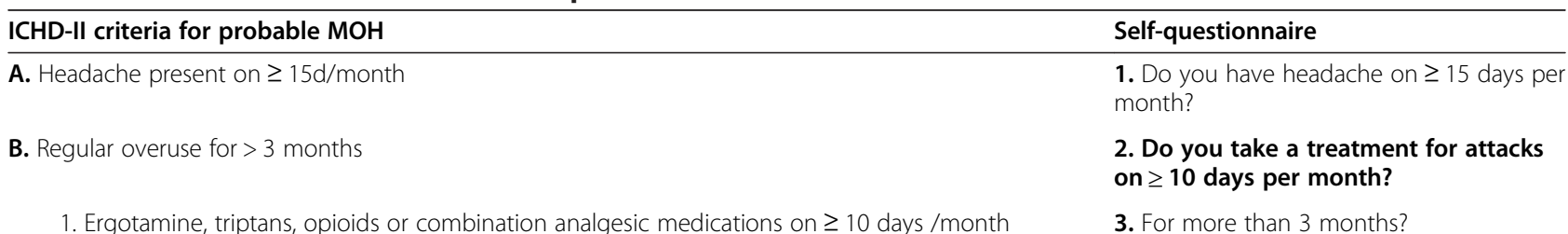
on a regular basis for 3 months

2. Simple analgesics or any combination of ergotamine, triptans, analgesics opioids on $\geq 15 \mathrm{D}$ per month on a regular basis for $>3$ months

4. Is this intake on a regular basis? 
sufficient sensitivity to detect most patients with $\mathrm{MOH}$ and sufficient specificity to minimize the number of patients who screen positive for $\mathrm{MOH}$ but do not have the condition. This tool must not be time-consuming or burdensome for routine investigation in pain clinics. Before the face-to-face with the neurologist, the nurse of the headache centre gave the questionnaire to the patients. The first step of the study was that each of the patients filled out the questionnaire unaided, and unknown to the neurologist. Then the face to face consultation was realized, the neurologist didn't know the answers of the patient to the questionnaire during the face to face interview. The same procedures were used in both groups.

The gold standard used to test the validity of the questionnaire was the face to face diagnosis of probable $\mathrm{MOH}$ made by headache specialists, based on the second edition of the ICHD-II. The gold standard procedure included a medical history, a comprehensive neurological history and examination. Possible organic causes of headache were excluded through a general and a neurological examination and if needed complementary exams. The headache specialist completed a symptom checklist based on ICHD-II criteria and assigned a clinical diagnosis of migraine or migraine plus $\mathrm{MOH}$.

\section{Validity assessment and data analysis}

Filling out the questionnaire and the face to face interview were done the same day. As validity indicators, we calculated sensitivity, specificity and the positive and negative predictive values for each pair, trio of item and for the 4 items. The sensitivity corresponded to the percentage of all affirmative answers in the group of patients with $\mathrm{MOH}$ (ability of detection of $\mathrm{MOH}$ cases). The specificity corresponded to the percentage of negative answers in the group of subjects with migraine (ability of detection of non-suffering $\mathrm{MOH}$ patients). The positive predictive value corresponded to the percentage of patients with $\mathrm{MOH}$ who screened positive. The negative predictive value corresponded to the percentage of patients without $\mathrm{MOH}$ who screened negative. Data analysis was done using SAS 8.2 for windows.

\section{Results}

Patients were enrolled between September 2009 and December 2009. Eighty-nine patients have been seen for headache in the headache centre during this period.

Seventy-seven patients were pre-included, with twentyone men $(27.3 \%)$ and fifty-six women (72.7\%). Ages varied from 16 to 71 years, with mean age of 42.5 .

After being interviewed by the neurologists, 42 patients (55\%) have been considered as suffering from probable $\mathrm{MOH}, 35$ patient having migraine without medication overuse. There were more women with probable $\mathrm{MOH}$ than men $(60.7 \%$ vs. $39.3 \% \mathrm{p}=0.08)$.
The mean age in $\mathrm{pMOH}$ group was higher than in migraine group (46.7 (12.2) years vs. 37.4 (13.6) years, $\mathrm{p}=0.002)$. Patients were heterogeneous concerning the duration of the disease and concerning the kind of medication they overused (Table 2).

Next we determined sensitivity, specificity, positive predictive value, negative predictive value for each item, for each pair of item and for the items $1+2+4$.

The third question about the onset and duration of the drug intake was clearly not discriminating enough: 90.5\% of patients have answered yes to the third question, that's why item 3 has been marked out. Results are showed in Table 3.

Concerning patients with pMOH, 19 patients had a duration of medication overuse $>10$ years, 13 patients up to 10 years. Duration of pMOH didn't have any influence on answers to questions. Twenty-four patients had $\mathrm{pMOH}$ type 1 as mentioned Saper and Lake [6], 18 type 2. This had no impact on answers. Eight patients overused acetaminophen or NSAID, 10 overused an association of medications, 14 overused combinations, 9 overused triptans and one ergotamine. The size of the sample did not allow to study the impact of the type of medication on the response profile. Duration of $\mathrm{pMOH}$ and classification of pMOH type 1 or 2 had no impact on answers to questionnaire $(\mathrm{p}=0.07$ and $\mathrm{p}=0.01$ respectively).

\section{Discussion}

The main results of our study validation was the following: the association of question 2 (do you take a treatment for attacks more than 10 days per month?) and question 4 (is this intake on a regular basis?) had a

Table 2 Age, sex and onset for migraine patients and pMOH* patients

\begin{tabular}{|c|c|c|c|c|c|}
\hline & \multicolumn{2}{|c|}{ Migraine } & \multicolumn{2}{|c|}{$\mathrm{MOH}$} & \multirow[t]{2}{*}{$P$ valuet } \\
\hline & $n=35$ & $\%$ & $n=42$ & $\%$ & \\
\hline Age (years) & 37.4 & 13.6 & 46.7 & 12.2 & 0.003 \\
\hline Male & 13.0 & 37.1 & 8.0 & 19.0 & 0.060 \\
\hline Female & 22.0 & 62.9 & 34.0 & 81.0 & \\
\hline \multicolumn{6}{|l|}{ Onset (years) } \\
\hline \multicolumn{6}{|l|}{$<10$ years } \\
\hline \multirow[t]{2}{*}{$>10$ years } & 10.0 & 28.6 & 19.0 & 45.2 & NA \\
\hline & 25.0 & 71.4 & 23.0 & 54.8 & NA \\
\hline \multicolumn{6}{|l|}{ Drug intake } \\
\hline Acetaminophen or NSAID & 2 & 25 & 6 & 17.6 & \\
\hline Combination & 2 & 25 & 12 & 20.6 & \\
\hline Triptans & 0 & & 9 & 35.3 & \\
\hline \multirow[t]{2}{*}{ Ergots opioids } & 1 & 12.5 & 0 & 26.5 & \\
\hline & 2 & 25 & 12 & 35.3 & \\
\hline
\end{tabular}

*probable Medication overuse headache. tComparison of means in student's test. 
Table 3 Sensitivity, specificity, positive predictive values, negative predictive values for each item and for more than one item

\begin{tabular}{|c|c|c|c|c|c|c|c|c|}
\hline \multirow[t]{2}{*}{ Question } & \multicolumn{2}{|c|}{ Sensitivity } & \multicolumn{2}{|c|}{ Specificity } & \multicolumn{2}{|l|}{ PPV* $^{*}$} & \multicolumn{2}{|l|}{$\mathrm{NPV}^{* *}$} \\
\hline & Absolute values & $\%$ & Absolute values & $\%$ & Absolute Values & $\%$ & Absolute values & $\%$ \\
\hline 1 & $34 / 42$ & 81.0 & $29 / 34$ & 85.3 & $34 / 49$ & 87.2 & $29 / 37$ & 78.4 \\
\hline 2 & $40 / 42$ & 95.2 & $26 / 34$ & 76.5 & $40 / 48$ & 83.3 & $26 / 28$ & 92.9 \\
\hline 3 & $40 / 41$ & 97.6 & $6 / 33$ & 18.2 & $40 / 67$ & 59.7 & $6 / 7$ & 85.7 \\
\hline 4 & $41 / 42$ & 97.6 & $12 / 35$ & 34.3 & $41 / 64$ & 64.1 & $12 / 13$ & 92.3 \\
\hline \multicolumn{9}{|c|}{ Yes for each question } \\
\hline $1+2$ & $34 / 42$ & 81.0 & $33 / 34$ & 97.1 & $34 / 35$ & 97.1 & $33 / 41$ & 80.5 \\
\hline $1+4$ & $35 / 43$ & 81.4 & $34 / 35$ & 97.1 & $34 / 35$ & 97.1 & $34 / 42$ & 81.0 \\
\hline $2+4$ & $40 / 42$ & 95.2 & $28 / 35$ & 80.0 & $40 / 47$ & 85.1 & $28 / 30$ & 93.3 \\
\hline $1+2+4$ & $34 / 42$ & 81.0 & $35 / 35$ & 100.00 & $34 / 34$ & 100.00 & $35 / 43$ & 81.4 \\
\hline
\end{tabular}

*positive predictive value.

**negative predictive value.

sensitivity of $95.2 \%$ and a specificity of $80 \%$. The advantages of such questions are their simplicity, rapidity, and low cost. Our sample of migraineurs, and of pMOH sufferers were heterogeneous in terms of age, sex, and duration. Moreover, we kept equivocal cases.

Several limitations of the results have to be discussed: At first, possible selection bias could exist: in a tertiary centre, patients could have a better knowledge of their disease, and could answer easier yes to the different questions, with better understanding, and therefore would be more able to quantify their medication intake. That could increase positive answers and then explain an increase of their sensibility in a tertiary centre. Moreover, patients seeking care in tertiary centres could have more severe disease, more severe medication overuse leading again to an increase in the questionnaire sensibility. For these reasons, generalisability to a populationbased setting need to be further tested. Secondly problems with the measures have to be considered: concerning the construction of the questionnaire, the criteria specifying the necessity of having developed a worsening of the headaches during overuse was not kept. Indeed, patients usually answered that if they take medication, it is because they have headaches and not the opposite [7]. Patients usually think that medication overuse is the result of an unrecognized or inadequate treatment of a primary headache disorder. Moreover it is a retrospective question, about a period sometimes many years before the diagnosis of pMOH. However, to evaluate the reliability of transforming the criteria of having developed a worsening of the headaches during overuse, we did a pretest in a sample of 10 patients, asking them if they have developed worsening of the headaches during overuse asking them if they understood the question. The results of this pretest are shown in Table 4. Five patients answered that they didn't develop a worsening of headaches during overuse, 2 patients answered that they did not know. That's why this criterion was not kept. In the same way, we evaluated the ability to understand the other questions by the patients. Are expressions such as treatment for attacks intake on a regular basis easily understandable for patients without any medical knowledge? We did a second pilot study on a sample of 24 patients testing the comprehensibility of both these expressions: namely the expression treatment for attack was understood by 22 patients. The expression "intake on a regular basis" was understood by all, except one patient. At the end, if we do the hypothesis on a decrease of sensitivity in the general population, what could be the outcome of false positives, i.e. patients with an intake below 10 days per month, on the border of medication overuse: could it

Table 4 Answers to the question concerning the criteria specifying the necessity of having developed a worsening of the headaches during overuse: results of the pilot study in $\mathbf{1 0}$ patients suffering from $\mathrm{pMOH}$

\begin{tabular}{lll}
\hline Patient & $\begin{array}{l}\text { Understanding of the } \\
\text { question (Yes/No) }\end{array}$ & $\begin{array}{l}\text { Answer to the question } \\
n^{\circ} 1\end{array}$ \\
Yes & $\begin{array}{l}\text { No, because had tried to decrease } \\
\text { the intake as early as the worsening } \\
\text { of headaches } \\
\text { Doesn't know }\end{array}$ \\
$n^{\circ} 2$ & Yes & No \\
$n^{\circ} 3$ & Yes & Yes \\
$n^{\circ} 4$ & Yes & Yes \\
$n^{\circ} 5$ & Yes & No \\
$n^{\circ} 6$ & Yes & Doesn't know \\
$n^{\circ} 7$ & Yes & Yes \\
$n^{\circ} 8$ & Yes & No \\
$n^{\circ} 9$ & Yes & No, because already tries to decrease \\
$n^{\circ} 10$ & Yes & drug consumption \\
\hline
\end{tabular}


Table 5 Methods used to diagnose MOH in main epidemiological studies

\begin{tabular}{|c|c|c|c|c|c|}
\hline Author & Country & Population & Questions or criteria & MOH Diagnosis & Type of questionnaire \\
\hline \multirow[t]{3}{*}{ Castillo 1999} & \multirow[t]{3}{*}{ Spain } & \multirow[t]{3}{*}{ Random sample 2252 patients } & Two questions: & \multirow{3}{*}{$\begin{array}{l}\text { Face-to-face diagnosis by a } \\
\text { neurologist interested in } \\
\text { headache }\end{array}$} & \multirow[t]{3}{*}{ Unvalidated Questionnaire } \\
\hline & & & 1- Have you ever had headache? & & \\
\hline & & & 2- Do you have headache tend days or more per month? & & \\
\hline Wang 2000 & Taiwan & $\begin{array}{l}\text { Population of a small islet }>65 \\
\text { years-old }\end{array}$ & Revision HIS criteria proposed by Silberstein & $\begin{array}{l}\text { Person-to-person survey } \\
\text { method and diagnosis by a } \\
\text { neurologist }\end{array}$ & Unvalidated Questionnaire \\
\hline \multirow[t]{2}{*}{ Lu 2001} & \multirow[t]{2}{*}{ Taiwan } & \multirow[t]{2}{*}{ Random population based survey } & Face-to face questionnaire & \multirow{2}{*}{$\begin{array}{l}\text { Then face-to-face diagnosis } \\
\text { with a physician }\end{array}$} & \multirow[t]{2}{*}{ Unvalidated questionnaire } \\
\hline & & & $\begin{array}{l}\text { Headache being present for more than } 3 \text { days per week } \\
\text { in the previous year }\end{array}$ & & \\
\hline \multirow[t]{3}{*}{ Colas 2004} & \multirow[t]{3}{*}{ Spain } & \multirow[t]{3}{*}{ Quota sampling approach $>14$} & Have you ever had headache? & \multirow{3}{*}{$\begin{array}{l}\text { Then face-to-face diagnosis } \\
\text { with a physician }\end{array}$} & \multirow[t]{3}{*}{ Unvalidated questionnaire } \\
\hline & & & Do you have headache 10 or more days per month? & & \\
\hline & & & $\begin{array}{l}\text { If yes, to other questions: In the last three months have you } \\
\text { taken any analgesic for your head pain }\end{array}$ & & \\
\hline Hagen 2009 & Norway & $\begin{array}{l}\text { All inhabitants of a county of } \\
\text { Norway invited to answer to a } \\
\text { questionnaire }\end{array}$ & $\begin{array}{l}\text { Headache more than } 14 \text { days per month and use of analgesics } \\
4 \text { times per week or more }\end{array}$ & $\begin{array}{l}\text { Then face to face interview } \\
\text { by a neurologist }\end{array}$ & $\begin{array}{l}\text { Validated questionnaire: sensitivity } \\
75 \% \text {, specificity } 100 \%\end{array}$ \\
\hline Straube 2010 & Germany & Adults from 3 German regions & $\begin{array}{l}14 \text { single items designed to assess the } 2 \text { nd ed of } \mathrm{IHS} \text {, medication } \\
\text { overuse classified based on medication intake during the last month. }\end{array}$ & $\begin{array}{l}\text { Face-to-face by trained } \\
\text { interviewers }\end{array}$ & $\begin{array}{l}\text { Kappa statistics was calculated: } \\
94.5 \% \text { indicating excellent inter-rater } \\
\text { agreement }\end{array}$ \\
\hline Jonsson 2011 & Sweden & Randomized cluster sampling & $\begin{array}{l}\text { Two screening questions: headache present on } \geq 15 \text { days per month } \\
\text { and using medication for } \geq 10 \text { days per month during the past } \\
\text { three months }\end{array}$ & Then subsequent interview & Unvalidated questionnaire \\
\hline
\end{tabular}


have negative implications for the patients wrongly classified as having pMOH by the questionnaire? In fact, it could have positive repercussions for the patients, with a primary or secondary preventive effect on the risk of developing $\mathrm{pMOH}$. Concerning false negative patients, they will continue their overuse, until they see a neurologist or another physician. In our study, sensitivity and specificity could be high because of the sole inclusion of migraine sufferers, without including other primitive headaches, such as cluster headache and tension-type headaches. But, for a pilot study, it is acceptable to have included only migraine patients and $\mathrm{CH}$ frequency in tertiary centre only. What improvements does this questionnaire have in comparison to other published questionnaire: Table 5 presents data about the methods used in main epidemiological studies concerning $\mathrm{MOH}[5,8-13]$. For each study, we specified the questions or criteria used for the $\mathrm{MOH}$ diagnosis, and specified if these questions were validated or not. One can notice that the only author using a validated questionnaire was Hagen [14]. In the general population he determined the diagnostic performances of the association of 2 questions: headaches which are present for more than 14 days per month and the use of analgesics 4 times per week or more. With such an association, a lower sensitivity was found: $75 \%$, specificity was $100 \%$. Other questionnaires do exist [14-17], but they concern research on dependence $[15,16]$. Radat et al. [15] constructed and validated a questionnaire measuring dependence on analgesics and on migraine treatments in headache patients. It measures with 21 questions a global dimension of dependence in $\mathrm{MOH}$ sufferers, but does not allow for giving a cut-off on which patients should be considered to have $\mathrm{MOH}$. Such a dependence questionnaire which focus on the dimension of dependence are more time-consuming, and maybe more difficult to administrate in current care, neither in tertiary nor in primary care settings. Maizels in 2003 [18] proposed a paradigm for the clinical application of a brief headache screening tool. Questions were open and medication overuse was correctly identified in $86 \%$ of patients with a specificity of $79 \%$. In this context, the advantages of this screening tool are its shortness, it's easy administration without much paper work and low cost. We must consider its diagnostic performances outside tertiary centre, i.e. neurologists outside hospitals, general practitioners, and maybe for patients themselves outside of any health place. In particular, predictive values have to be determined in the general population. To conclude, we validated a screening tool in the French version for the diagnosis of $\mathrm{pMOH}$. In the future, an English version should be validated.

\section{Competing interests}

The authors declare that they have no competing interest.

\section{Authors' contributions}

VD carried out the study, MM participated to interpretation of data, ML and JFD participated in the design of the study and performed the statistical analysis. FR and BB participated in the design of the study. TK helped to draft the manuscript. All authors read and approved the final manuscript.

\section{Author details}

${ }^{1}$ Centre Douleur Chronique, Hôpital Pellegrin, Place Amélie Raba Léon, 33 076 Bordeaux, Cedex, France. ${ }^{2}$ Inserm Unit 593, Neuroepidemioloy, Paris, France. ${ }^{3}$ University of Bordeaux, Bordeaux, France. ${ }^{4}$ Inserm Unit 708, Neuroepidemiology, Bordeaux, France.

Received: 14 February 2013 Accepted: 16 September 2013 Published: 2 October 2013

\section{References}

1. Schmid CW, Maurer K, Schmid DM, Alon E, Spahn DR, Gantenbein AR, Sandors PS (2013) Prevalence of medication overuse headache in an interdisciplinary pain clinic. J Headache Pain 14:4

2. Lanteri-minet M, Duru G, Mudge M, Cottrell S (2011) Quality of life impairment, disability and economic burden associated with chronic daily focusing on chronic migraine with or without medication overuse: a systematic review. Cephalalgia 31(7):837-850

3. Silberstein SD, Olesen J, Bousser MG et al (2005) International headache society. The international classification of headache disorders, 2nd edition (ICHD-II) revision of criteria for 8.2 Medication-overuse headache. Cephalalgia 25:460-465

4. Olesen J et al (2006) New appendix criteria open for a broader concept of chronic migraine. Cephalalgia 26:742-746

5. Evers S, Marziniak M (2010) Clinical features, pathophysiology, and treatment of medication overuse headaches. Lancet Neurol 9:391-401

6. Saper JR, Lake AE (2006) Medication overuse headache: type 1 and type 2. Cephalalgia 26:1262

7. Jonsson P, Jakobson A, Hensing G, Linde M, Moore CD, Hedenrud T (2013) Holding on to the indispensable medication - a grounded theory on medication use from the perspective of persons with medication overuse headache. J Headache Pain 14:43

8. Castillo J, Munoz P, Guitera V, Pascual J (1999) Epidemiology of chronic daily headache in the general population. Headache 39:190-196

9. Wang SJ (2003) Epidemiology of migraine and other types of headaches in Asia. Current Neurol Neurosci reports 3:104-108

10. Lu SR, Fuh JL, Chen WT, Juang KD, Wang SJ (2001) Chronic daily headache in Taipei, Taiwan: prevalence, follow-up and outcome predictors. Cephalalgia 21:980-986

11. Colas R, Munoz R, Temprano R et al (2004) Chronic daily headache with analgesic overuse: epidemiology and impact on quality of life. Neurol 62:1338

12. Straube A, Pfaffenrath $V$, Ladwig KH, Hoffmann W, Fendrich $K$, Vennemann M, Berger K (2010) Prevalence of chronic migraine and medication overuse headache in Germany-The German DMKG headache study. Cephalalgia 30 (2):207-213

13. Jonsson P, Hedenrud T, Linde M (2011) Epidemiology of medication overuse headache in the general Swedish population. Cephalalgia 9:1015-1022

14. Hagen $\mathrm{K}$ et al (2010) The validity of questionnaire-based diagnoses: the third Nord Trondelag health study 2006-2008. J Headache Pain 11(1):67-73

15. Radat F et al (2006) Construction of a medication dependence questionnaire in headache patients (MDQ-H): validation of the French version. Headache 46:233-239

16. Lundqvist C, Benth JS, Grande RB, Aaseth K, Russel MB (2011) An adapted severity of dependence scale is valid for the detection of medication overuse: the Akershus study of chronic headache. Eur J Neurol 18(3):512-518

17. Wallasch TM, Hermann C (2012) Validation of criterion-based patient assignment and treatment effectiveness of a multidisciplinary modularized managed care program for headache. J headache Pain 5:379-387

18. Maizels M et al (2003) Rapid and sensitive paradigm for screening patients with headache in primary care settings. Headache 43:441-450

doi:10.1186/1129-2377-14-81

Cite this article as: Dousset et al:: Probable medications overuse headaches: validation of a brief easy-to-use screening tool in a headache centre. The Journal of Headache and Pain 2013 14:81. 